Article

\title{
On the MHD Casson Axisymmetric Marangoni Forced Convective Flow of Nanofluids
}

\author{
Anum Shafiq ${ }^{1}$ (D), Islam Zari ${ }^{2}$, Ghulam Rasool ${ }^{3}$ (D) , Iskander Tlili ${ }^{4,5, *}$ and Tahir Saeed Khan ${ }^{2}$ \\ 1 School of Mathematics and Statistics, Nanjing University of Information Science and Technology, \\ Nanjing 210044, China; anumshafiq@ymail.com \\ 2 Department of Mathematics, University of Peshawar, Khybar Pakhtunkhwa 25000, Pakistan; \\ zari145@yahoo.com (I.Z.); tsk7@uop.edu.pk (T.S.K.) \\ 3 School of Mathematical Sciences, Yuquan Campus, Zhejiang University, Hangzhou 310027, China; \\ grasool@zju.edu.cn \\ 4 Department for Management of Science and Technology Development, Ton Duc Thang University, \\ Ho Chi Minh City 758307, Vietnam \\ 5 Faculty of Applied Sciences, Ton Duc Thang University, Ho Chi Minh City 758307, Vietnam \\ * Correspondence: iskander.tlili@tdtu.edu.vn
}

Received: 26 September 2019; Accepted: 8 November 2019; Published: 11 November 2019

\begin{abstract}
The proposed investigation concerns the impact of inclined magnetohydrodynamics (MHD) in a Casson axisymmetric Marangoni forced convective flow of nanofluids. Axisymmetric Marangoni convective flow has been driven by concentration and temperature gradients due to an infinite disk. Brownian motion appears due to concentration of the nanosize metallic particles in a typical base fluid. Thermophoretic attribute and heat source are considered. The analysis of flow pattern is perceived in the presence of certain distinct fluid parameters. Using appropriate transformations, the system of Partial Differential Equations (PDEs) is reduced into non-linear Ordinary Differential Equations (ODEs). Numerical solution of this problem is achieved invoking Runge-Kutta fourth-order algorithm. To observe the effect of inclined MHD in axisymmetric Marangoni convective flow, some suitable boundary conditions are incorporated. To figure out the impact of heat/mass phenomena on flow behavior, different physical and flow parameters are addressed for velocity, concentration and temperature profiles with the aid of tables and graphs. The results indicate that Casson fluid parameter and angle of inclination of MHD are reducing factors for fluid movement; however, stronger Marangoni effect is sufficient to improve the velocity profile.
\end{abstract}

Keywords: Casson nanoliquid; Marangoni convection; inclined MHD; Joule heating; heat source

\section{Introduction}

The theory of magnetohydrodynamics (MHD) is highly appreciated for the industrial purposes. It is based on magnetic properties of electrically conducting liquids. The characteristic of MHD field is to generate currents in moving liquid and produce forces that act upon the liquid flow and reconstruct the magnetic field itself. To modify flow features of heat and mass analysis, the applied magnetic field impacts the deferred nanoparticles and reforms their absorption inside the liquid. This efficient phenomenon was first utilized for astrophysical and geophysical related problems. Recently, heat transportation and MHD flows have played significant roles in agricultural engineering, petroleum industries and medical treatment such as MHD strategy used for reduction of blood during surgeries, magnetic cell separation and treatment of certain arterial diseases. Basically, the MHD parameter is not only working as a significant parameter to control the cooling/heating rate but also to achieve desired quality of product for different flows. Further, MHD can be used in continuous casting of metal 
processing to suppress instabilities and control flow field. In this context, Hayat et al. [1,2] explored the MHD flow through moving surfaces and concluded that enhancement in magnetic parameter shows increase in nanoparticles concentration and temperature profiles. Hayat et al. [3,4] numerically studied heat transfer impact on MHD axisymmetric third grade liquid flow. Shafiq et al. [5] presented the study of bioconvective MHD tangent hyperbolic nanoliquid flow with Newtonian heating. Shateyi and Makinde [6] prepared MHD stagnant point flow through a radially stretching convectively heated disk. Hayat et al. [7] investigated the third grade axisymmetric MHD flow over a stretched cylinder and showed that momentum layer thickness and velocity profile are increasing when the curvature parameter increases. Moreover, Shafiq et al. [8] discussed magnetohydrodynamics axisymmetric third grade liquid flow between two porous disks.

The novelty of Marangoni convection is generally the edge dissipative layer between two phase fluid flows such as gas-liquid and liquid-liquid interfaces. It depends upon the variation of surface tension driven by temperature, chemical concentration and applied magnetic field. These gradients can occur only when fluid interfaces contain different fluid properties from each other. Due to the viscosity of interacting liquids, external forces such as gravitational and shear forces come into action. Most researchers have focused their interest on simulating these external forces by utilizing governing equations due to its widespread application in the fields of space processing, industrial manufacturing processes and microgravity science. The significance of Marangoni convective flows in the transportation process of heat and mass into different systems have been thoroughly scrutinized in [9-11]. Kumar et al. [12] discussed Marangoni convective Casson nanoliquid flow in the presence of chemical reaction and uniform heat source/sink and observed that Marangoni parameter showed dominant behavior in terms of velocity as well as temperature fields. Din et al. [13] examined the effect of Marangoni convection on based nanoliquid with thermal radiation and demonstrated that decreasing behavior of velocity profile depends on suction parameter, whereas the temperature distribution and boundary layer thickness increased with an increase in nanofluid volume fraction. Sheikholeslami and Ganji [14] studied the impact of magnetic field on nanoliquid flow by Marangoni convection by Runge-Kutta technique and observed that an increment in heat transfer depended on an increment in solid volume fraction of nanofluid. Hayat et al. [15] investigated the impact of radiation and Joule heating on Marangoni mixed convective flow.

For the last few decades, survey of non-Newtonian fluid flows has been the center of attraction for researchers, engineers and scientists. This is due to the application of non-Newtonian liquid flows in the real world, e.g., in bio-engineering, drilling operations, plastic polymers, paint, optical fibers, coated sheets, cosmetics, salt solutions, food item, etc. The existing problems in nature related with larger diameter and higher shear rates can be solved easily; however, when these flows are related to small diameter with low shear rates, the importance of non-Newtonian fluids (see $[16,17])$ are non-negligible. The deviation from classical Newton's law of viscosity and flow behavior under shear stress to the non-Newtonian fluids become complex. These flows are challenging task for researchers due to their non-linear rheological behavior. Casson liquid model is one of simplest models of non-Newtonian fluids. The idea of Casson fluid administrated by Casson (see [18]) is to build up the blood flow problems. Due to its rheological properties, Casson liquid behaves as a soft solid when yield stress is higher than shear stress, whereas, if shear stress approaches to infinity, then it starts to deform (see [19]). This structure is widely used for different materials, such as jelly, chocolate, honey, blood, tomato sauce and condensed fruit juices. Charm and Kurland [20] used Casson fluid model and investigated the viscosity of human blood. Bhattacharyya and Hayat [21] analyzed the Casson fluid on MHD boundary layer flow through shrinking sheet. Kumar et al. [22] investigated the viscous dissipation phenomenon in Casson nanoliquid over a moving radiative surface. Moreover, Casson fluid flow model [23-25] has been considered for different geometries and various effects in the literature.

The introduction of nanoparticles in different systems is most favorable to intensify thermal conductivity of classical liquid flows, convection heat transfer coefficient and to control loss in energy. 
The advantages of nanosize particles in fluid systems is to increase surface area, capacity of heat transfer, intensify the flow interface after collision and interact fluid particles with each other. Thus, this phenomenon is a backbone of the industrial processes and is also beneficial for solar energy resources and bio-medical treatment (see [26-34]). The proficiency of the solar systems [35] can be improved by incorporating the nanoparticles as working fluid into the systems. The iron based nanoparticles may be utilized as drug and radiation transportation for the treatment of cancer patient (see [36,37]). Using magnets the particles can be enter through blood stream to tumor. This type of cancer treatment permits high local doses of drugs into the body without any significant side effect. Further, micelles nanoparticles have been recently introduced to target the kidney cells diseases. These particles can pass into the kidney and remain there. Similarly, magnetic based nanoparticles are also used for cell separation, hyperthermia therapies and for the increment in Magnetic Resonance Imaging (MRI) with contrast behavior. Hayat et al. [38] judged that nanofluid enhanced the temperature and associated boundary layer width of Casson flow. Naseem et al. [39] numerically investigated third grade nanoliquid flow using the Cattaneo-Christov model over a Riga plate and observed that, with an increment in thermal and concentration relaxation parameters, a reduction occurred in concentration and temperature distribution, respectively. Rasool et al. [40] examined the MHD Darcy-Forchheimer nanoliquid flow under the nonlinear stretched surface. Rashid et al. [41] investigated the entropy generation in Darcy-Forchheimer flow of nanofluid with five nanomaterials due to stretching cylinder. Naseem et al. [42] considered the MHD biconvective flow of a Powell-Eyring nanoliquid over a stretching plate. Rasool et al. [43-48] reported some interesting results involving the role of nanoparticles in typical base fluids flowing over different surfaces.

In the studies mentioned above, one can see that an utmost attention is given to natural convection and heat and mass transfer analysis but less importance has been given to the convection through Marangoni phenomena especially in nanofluid flows. The thermo-capillary and soluto-capillary affects are the main factors in Marangoni convection of fluids and nanofluids. Furthermore, flat surfaces with linear stretching are assumed frequently but axisymmetric analyses are less reported. The main contribution of this research is to examine the process of heat and mass transportation for axisymmetric Marangoni convective flow with an inclined MHD by taking Casson nanofluid flowing towards an infinite disk. Brownian motion and thermophoresis are deliberated on account of nanoparticles structure. Finally, the problem is solved by an accurate numerical technique known as Runge-Kutta fourth-order algorithm, whereas previous studies are given mostly by HAM.

\section{Problem Formulation and Coordinate System}

The geometry of the problem (see Figure 1) is based on the MHD effect for axisymmetric Marangoni convective, incompressible, steady and laminar flow utilizing the electrically conducting Casson nanoliquid model. Marangoni convective flow is caused due to concentration and temperature gradients on surfaces generated by surface tension. A uniform magnetic field is applied in such a way that it makes an angle $\alpha_{1}$ in non-vertical direction. The cylindrical coordinates system is considered along and normal to the interface of flow problem. Concentration and temperature interfaces of the flow structure are altered at the surface of the disk. The analysis of heat transfer is examined through Joule heating and viscous dissipation. The formulated governing equations for the MHD effect on Marangoni convective flow structure are given as (see, for example, [4-15]):

$$
\begin{gathered}
\frac{\partial \tilde{u}}{\partial \tilde{r}}+\frac{\partial \tilde{w}}{\partial \tilde{z}}+\frac{\tilde{u}}{\tilde{r}}=0, \\
\tilde{u} \frac{\partial \tilde{u}}{\partial \tilde{r}}+\tilde{w} \frac{\partial \tilde{u}}{\partial \tilde{z}}=\frac{\mu}{\rho}\left(1+\frac{1}{\beta_{1}}\right) \frac{\partial^{2} \tilde{u}}{\partial \tilde{z}^{2}}-\frac{\sigma B_{0}^{2}}{\rho} \sin ^{2} \alpha_{1} \tilde{u},
\end{gathered}
$$




$$
\begin{aligned}
\tilde{u} \frac{\partial \tilde{T}}{\partial \tilde{r}}+\tilde{w} \frac{\partial \tilde{T}}{\partial \tilde{z}}= & \frac{k}{\rho c_{\omega}} \frac{\partial^{2} \tilde{T}}{\partial \tilde{z}^{2}}+\tau \frac{D_{\tilde{T}}}{\tilde{T}_{\infty}}\left(\frac{\partial \tilde{T}}{\partial \tilde{z}}\right)^{2}+\tau D_{B} \frac{\partial \tilde{C}}{\partial \tilde{z}} \frac{\partial \tilde{T}}{\partial \tilde{z}}+\frac{1}{\rho c_{\omega}} Q_{1}\left(\tilde{T}-\tilde{T}_{\infty}\right) \\
& +\frac{\mu}{\rho c_{\omega}}\left(1+\frac{1}{\beta_{1}}\right)\left(\frac{\partial \tilde{u}}{\partial \tilde{z}}\right)^{2}+\frac{\sigma B_{0}^{2}}{\rho c_{\omega}} \sin ^{2} \alpha_{1} \tilde{u}^{2}, \\
& \tilde{u} \frac{\partial \tilde{C}}{\partial \tilde{r}}+\tilde{w} \frac{\partial \tilde{C}}{\partial \tilde{z}}=D_{B} \frac{\partial^{2} \tilde{C}}{\partial \tilde{z}^{2}}+\frac{D_{\tilde{T}}}{\tilde{T}_{\infty}} \frac{\partial^{2} \tilde{T}}{\partial \tilde{z}^{2}} .
\end{aligned}
$$

In Equations (1)-(4), $\rho$ characterizes fluid density; $\mu$ signifies dynamic viscosity; $\beta$ indicates parameter of Casson fluid; $\sigma$ symbolizes surface tension; $\tilde{C}$ and $\tilde{T}$ represent fluid concentration and temperature, respectively; $\tilde{C}_{\infty}$ and $\tilde{T}_{\infty}$ characterize fluid ambient concentration and temperature far away from the surface, respectively; $\tau$ shows shear stress; $D_{B}$ is the coefficient of Brownian diffusion; $k$ indicates coefficient of absorption; $c_{\omega}$ denotes specific heat; $D_{\tilde{T}}$ characterizes coefficient of thermophoretic diffusion; $Q_{1}$ represents heat source sink coefficient; and $\alpha_{1}$ signifies angle of inclination.

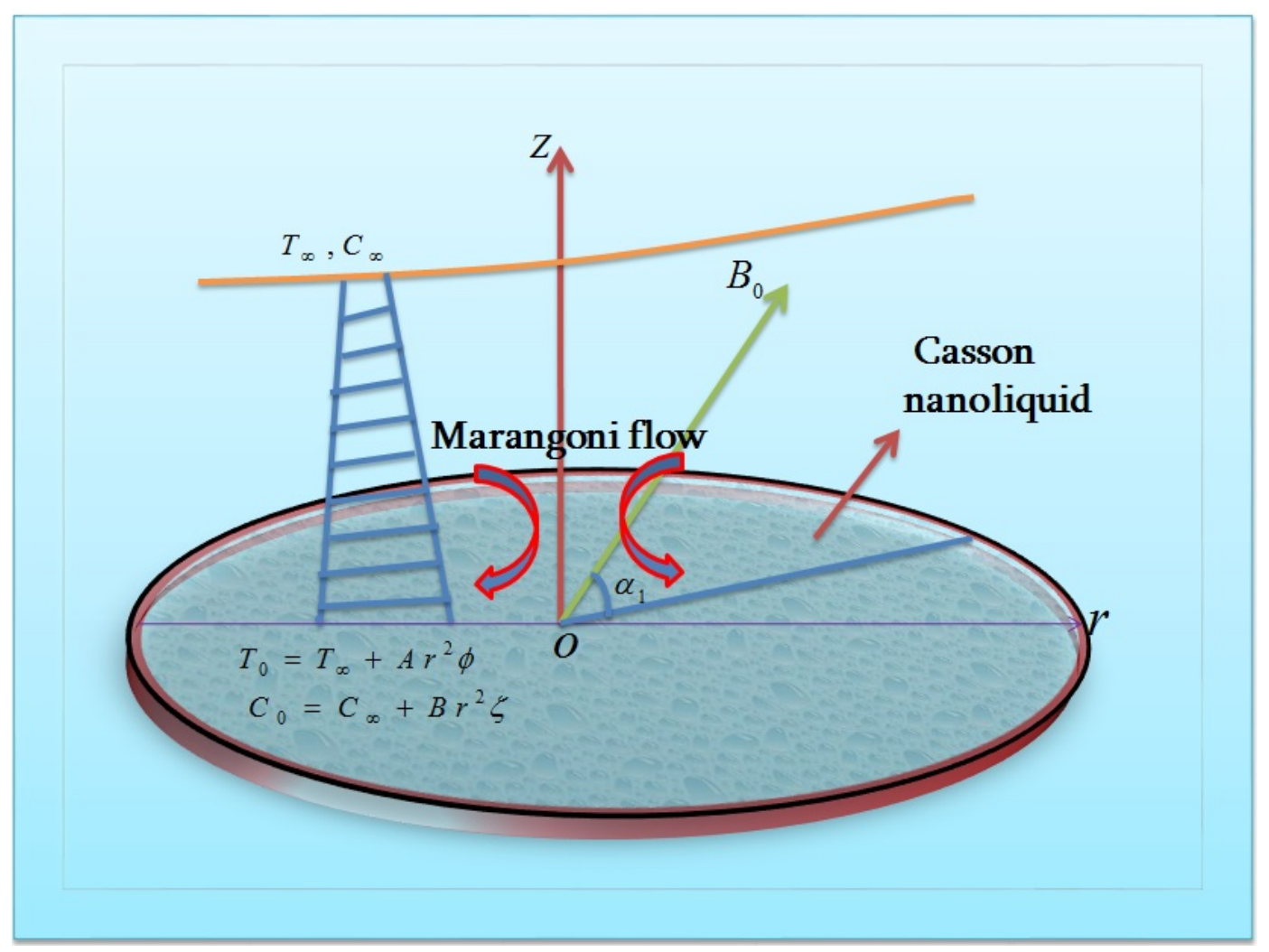

Figure 1. Physical diagram of the flow model.

The subjected boundary conditions are (see, for example, [10]):

$$
\begin{aligned}
\left.\mu\left(1+\frac{1}{\beta_{1}}\right) \frac{\partial \tilde{u}}{\partial \tilde{z}}\right|_{\tilde{z}=0} & =\left.\frac{\partial \sigma \partial \tilde{T}}{\partial \tilde{T}}\right|_{\tilde{T}=0}+\left.\frac{\partial \sigma}{\partial \tilde{C}} \frac{\partial \tilde{C}}{\partial \tilde{r}}\right|_{\tilde{z}=0},\left.\quad \tilde{w}\right|_{\tilde{z}=0}=0 \\
\left.\tilde{T}\right|_{\tilde{z}=0} & =\tilde{T}_{\infty}+A \tilde{r}^{2} \phi,\left.\quad \tilde{C}\right|_{\tilde{z}=0}=\tilde{C}_{\infty}+B \tilde{r}^{2} \zeta \\
\left.\tilde{u}\right|_{\tilde{z} \rightarrow \infty} & \longrightarrow 0,\left.\tilde{T}\right|_{\tilde{z} \rightarrow \infty} \longrightarrow \tilde{T}_{\infty},\left.\quad \tilde{C}\right|_{\tilde{z} \rightarrow \infty} \longrightarrow \tilde{C}_{\infty} .
\end{aligned}
$$


The suitable transformations incorporated in the proposed flow structure are (see, for example, [6]):

$$
\eta=\sqrt{\frac{b}{v}} \tilde{z}, \tilde{u}=b \tilde{r} g^{\prime}(\eta), \tilde{w}=-2 \sqrt{b v} g(\eta), \quad \zeta=\frac{\tilde{C}-\tilde{C}_{\infty}}{\tilde{C}_{g}-\tilde{C}_{\infty}}, \phi=\frac{\tilde{T}-\tilde{T}_{\infty}}{\tilde{T}_{g}-\tilde{T}_{\infty}} .
$$

Moreover, assumptions indicate that surface tension is a linear function of concentration and temperature, which may be represented as (see, for example, [10]):

$$
\sigma=\sigma_{0}-\gamma_{\tilde{T}}\left(\tilde{T}-\tilde{T}_{\infty}\right)-\gamma_{\tilde{C}}\left(\tilde{C}-\tilde{C}_{\infty}\right)
$$

where $\sigma_{0}, \gamma_{\tilde{T}}$ and $\gamma_{\tilde{C}}$ represent the positive constants. After incorporating the above-mentioned transformations into Equations (1)-(4), we obtain

$$
\begin{gathered}
\left(1+\frac{1}{\beta_{1}}\right) g^{\prime \prime \prime}+2 g g^{\prime \prime}-\left(g^{\prime}\right)^{2}-M_{1}^{2} \sin ^{2} \alpha_{1} g^{\prime}=0, \\
g(0)=0,\left(1+\frac{1}{\beta_{1}}\right) g^{\prime \prime}(0)=-2 M_{a}\left(1+R_{a} \zeta(0)\right), g^{\prime}(\infty)=0, \\
\phi^{\prime \prime}+2 \operatorname{Pr} g \phi^{\prime}+\operatorname{Pr} N_{1} \phi^{\prime} \zeta+\operatorname{Pr} N_{2}\left(\phi^{\prime}\right)^{2}+\operatorname{Pr} E c\left(1+\frac{1}{\beta_{1}}\right)\left(g^{\prime \prime}\right)^{2}+\operatorname{Pr} E c M_{1}^{2} \sin ^{2} \alpha_{1}\left(g^{\prime}\right)^{2}+\operatorname{Pr} B_{1} \phi=0, \\
\phi(0)=1, \phi(\infty)=0, N_{1}^{\prime} \zeta(0)+N_{2} \phi^{\prime}(0)=0, \\
\zeta^{\prime \prime}+2 L e g \zeta^{\prime}+\frac{N_{2}}{N_{1}} \phi^{\prime \prime}=0, \\
\zeta(0)=1, \zeta(\infty) \rightarrow 0 .
\end{gathered}
$$

In Equations (8)-(13), $N_{1}=\frac{\tau D_{B}\left(\tilde{C}_{g}-\tilde{C}_{\infty}\right)}{v}$ indicates Brownian motion parameter, $N_{2}=\frac{\tau D_{\tilde{T}}\left(\tilde{T}_{g}-\tilde{T}_{\infty}\right)}{v \tilde{T}_{\infty}}$ characterizes thermophoresis parameter, $M_{1}=\frac{\sigma B_{0}^{2}}{8 \rho b}$ shows magnetic number, $M_{a}=\frac{\gamma_{\tilde{T}}}{\mu \Omega} \sqrt{\frac{\Omega}{\gamma}}$ signifies Marangoni number, $R_{a}=\frac{\gamma_{\tilde{T}} B}{\gamma_{\tilde{T}} A}$ shows Marangoni ratio parameter, $B_{1}=\frac{Q}{h \rho c_{\omega}}$ represents heat source sink, $\operatorname{Pr}=\frac{\rho c_{\omega} \mu}{k}$ signifies Prandtl number, $E c=\frac{\breve{u}_{\infty}^{2}}{c_{\omega}\left(\tilde{T}_{w}-\tilde{T}_{\infty}\right)}$ indicates Eckert number, and $L e=\frac{v}{D_{B}}$ denotes Lewis number. Additionally, $N u$ the local Nusselt number is given as

$$
N u=\frac{-\left.\tilde{r}\left(\frac{\partial \tilde{T}}{\partial \tilde{z}}\right)\right|_{\tilde{z}=0}}{k\left(\tilde{T}_{\infty}-\tilde{T}_{w}\right)}
$$

and in dimensionless form becomes

$$
R_{d}^{-1 / 2} N u=\frac{N u}{\sqrt{R_{d}}}=-\phi^{\prime}(0),
$$

where $R_{d}=\frac{\tilde{u}_{v} \tilde{r}}{v}$ is local Reynold's parameter.

\section{Computational Scheme}

We now solve the governing Equations (8)-(13), numerically by employing Runge-Kutta fourth-order technique. For different sundry parameters, we perform numerical computation.

\section{Physical Interpretation and Analysis}

The main objective of this segment is to communicate the physical importance of heat and mass transportation phenomenon in axisymmetric Marangoni convective flow with the impact of inclined MHD on Casson nanoliquid over an infinite disk. To clearly check the insight of proposed model, the 
impact of different parameters (Casson fluid parameter $\beta_{1}$, magnetic number $M_{1}$, angle of inclination $\alpha_{1}$, Marangoni number $M_{a}$, Brownian motion parameter $N_{1}$, thermophoresis parameter $N_{2}$, Prandtl number Pr, heat source sink $B_{1}$ and Lewis number $L e$ ) are considered on velocity field $g(\eta)$, temperature profile $\phi(\eta)$, concentration distribution $\zeta(\eta)$ and local Nusselt number $N u$.

\subsection{Assessment of Velocity Distribution}

The performance of Casson fluid parameter $\beta_{1}$ on velocity field $g^{\prime}(\eta)$ is demonstrated in Figure 2. In this figure, one can see that, for enhancement in $\beta_{1}$, velocity profile increases near the wall but decreases when $\eta>1.4$ and vanishes far away from the surface. This is because an increment in Casson fluid parameter produces a decrease in yield stress and the fluid adopts rheological behavior and associated boundary layer width reduces. In Figure 3, it is analyzed that a rise in magnetic parameter $M_{1}$ drops the fluid velocity. This logic is dependent on the fact that an increment in magnetic field $M_{1}$, which causes an increase in the resistive nature of Lorentz force, and consequently decreases the velocity field. Figure 4 demonstrates the influence of inclination angle $\alpha_{1}$ on $g^{\prime}(\eta)$. It is apparent from the sketch that velocity profile $g^{\prime}(\eta)$ reduces when the angle of inclination $\alpha_{1}$ increases. This is because, when angle of inclination increases, the impact of magnetic field rises on liquid and as a result Lorentz force increases, which in turn decreases the velocity profile. In addition, for $\alpha_{1}=0$, there is no effect of magnetic field on velocity profile, whereas, for $\alpha_{1}=\pi / 2$, maximum resistance is noted. In Figure 5 , graphical representation signifies that velocity field is mounting function of Marangoni number $M_{a}$. This behavior is because of Marangoni number, as it is the ratio between tangential stress and viscosity. Therefore, the fluid with higher surface tension acts more strongly on the surrounding liquid and consequently it enhances velocity of the fluid.

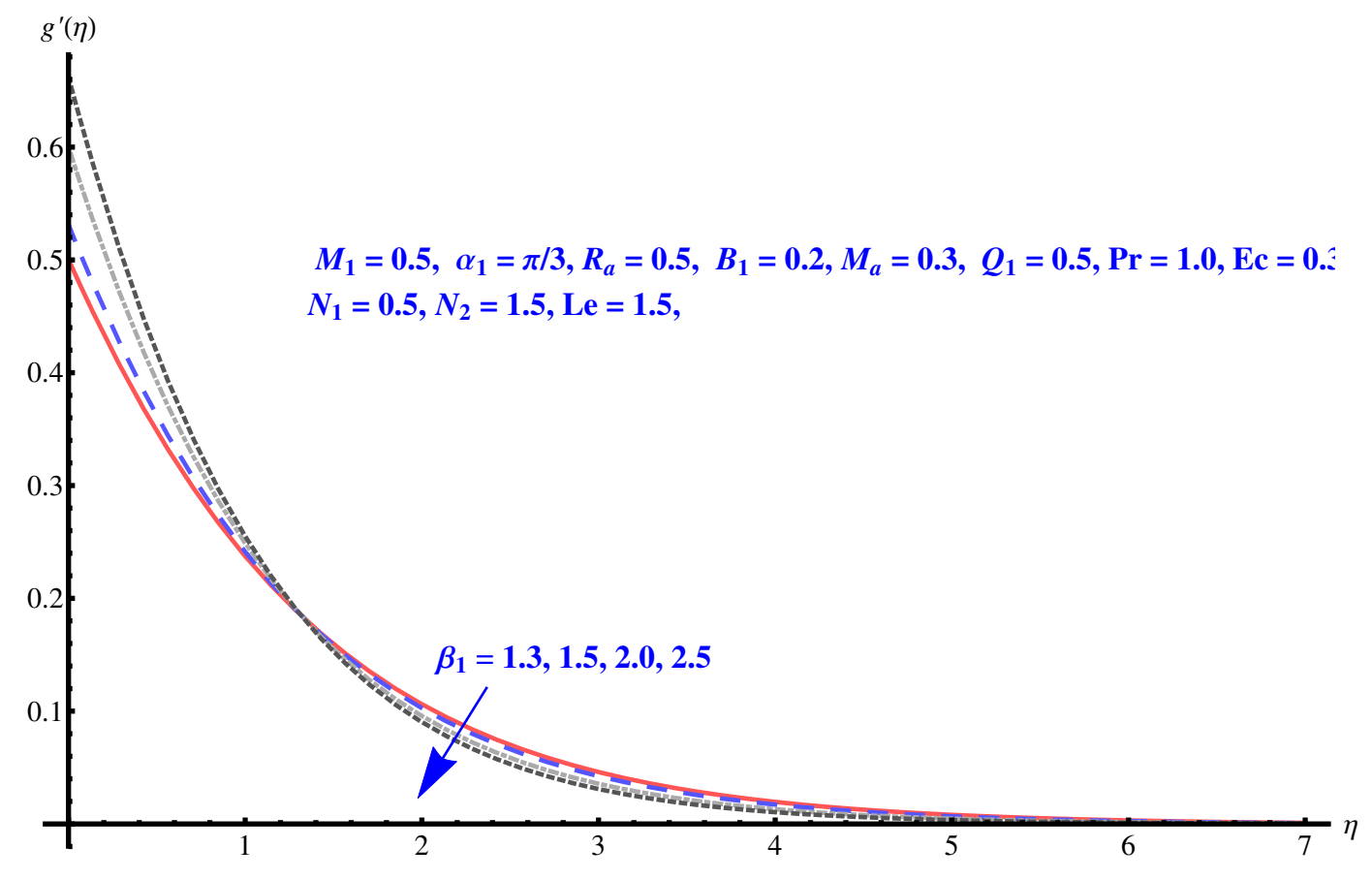

Figure 2. Influence of $\beta_{1}$ on velocity field. 


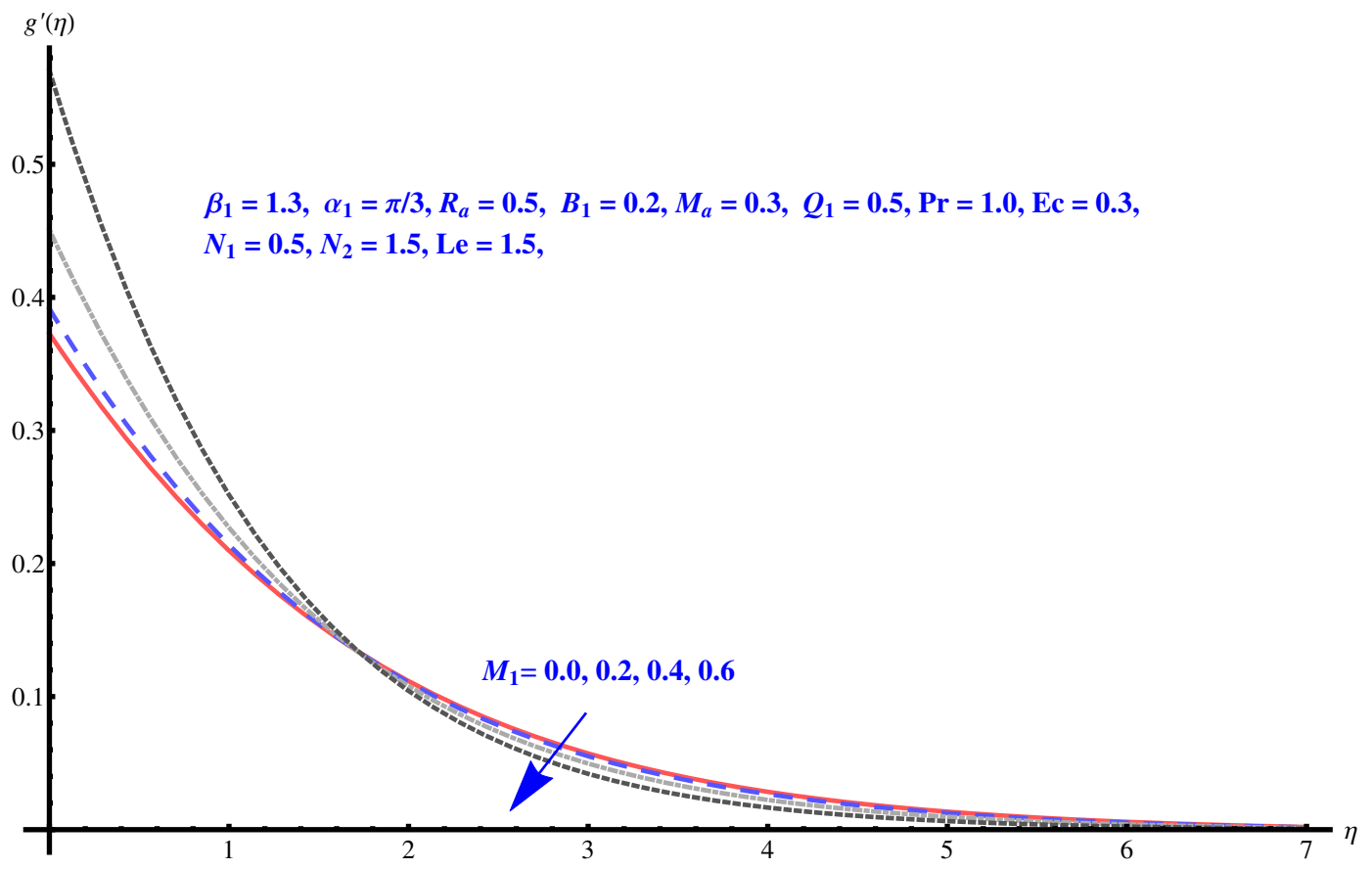

Figure 3. Influence of $M_{1}$ on velocity field.

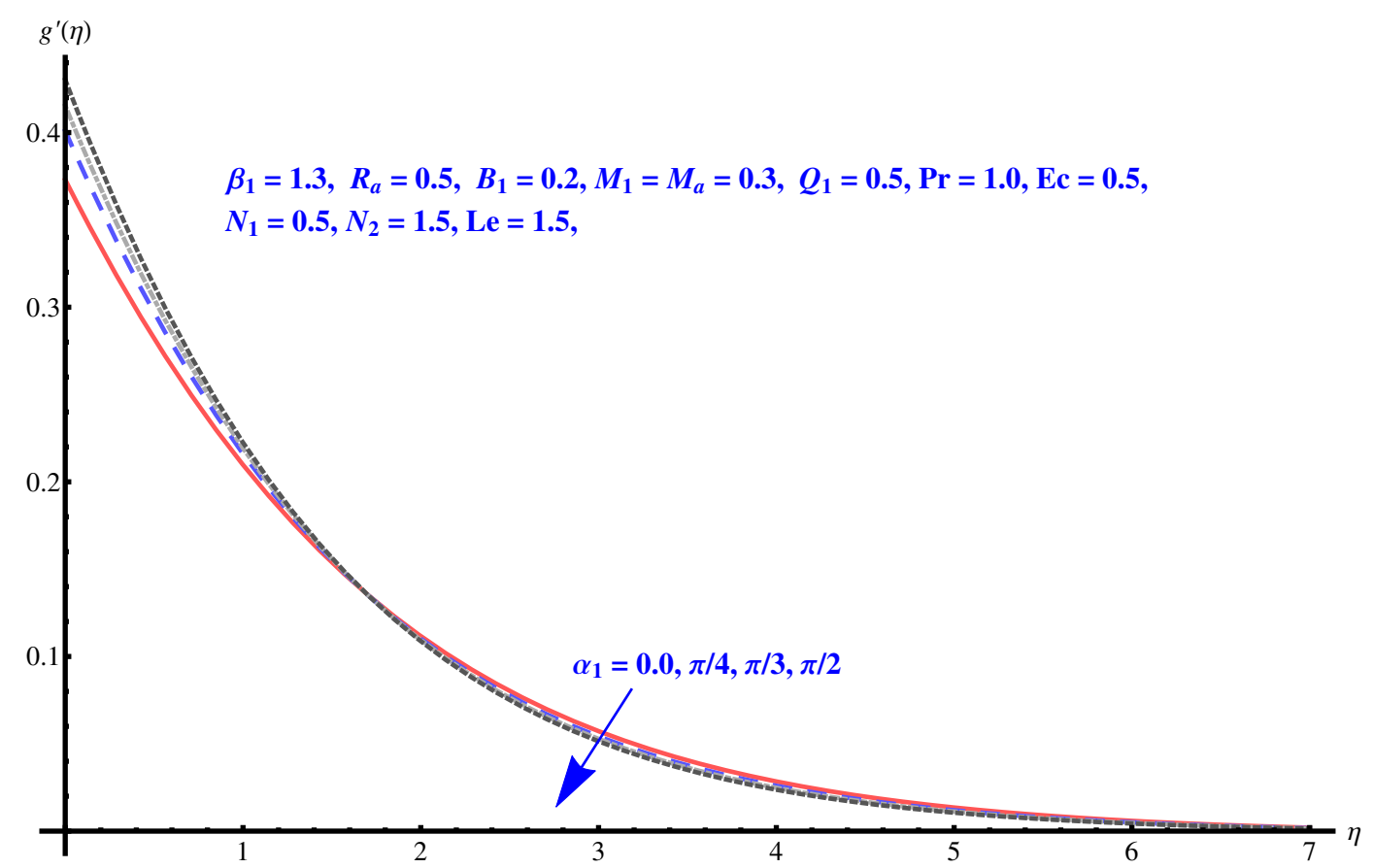

Figure 4. Influence of $\alpha_{1}$ on velocity field. 


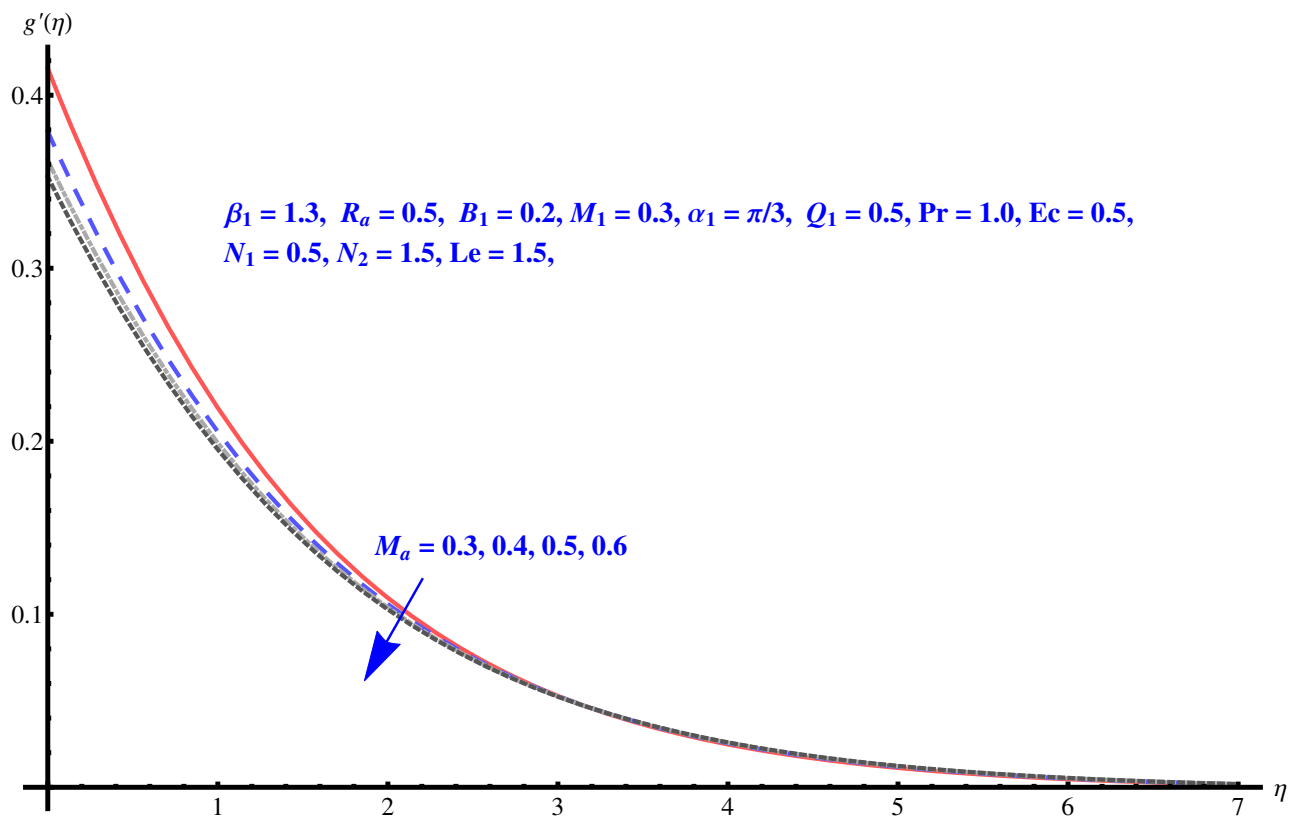

Figure 5. Influence of $M_{a}$ on velocity field.

\subsection{Assessment of Temperature Distribution}

In this subsection, the temperature field $\phi(\eta)$ corresponds to various sundry parameter such as thermophoresis parameter $N_{2}$, Brownian motion parameter $N_{1}$ and heat source parameter $B_{1}$ are plotted in Figures 6-8. The behavior of $N_{1}$ on $\phi(\eta)$ is sketched in Figure 6. The temperature field $\phi(\eta)$ is increased with a rise in Brownian motion parameter $N_{1}$. With the increment in Brownian motion parameter, the fluid molecules becomes more energetic. As a result, the temperature field is enhanced. Figure 7 shows the significance of Thermophoresis parameter $N_{2}$ on $\phi(\eta)$. It is noted that the temperature field is a mounting function of $N_{2}$. Figure 8 shows the variation of heat source $B_{1}$ via temperature field $\phi(\eta)$. It is examined that temperature as well as the associated boundary layer is increased by increment in heat source parameter $B_{1}$. Physically, the rise in rate of heat source parameter $B_{1}$ leads to the thermal boundary layer thickness becoming greater, as does the temperature field.

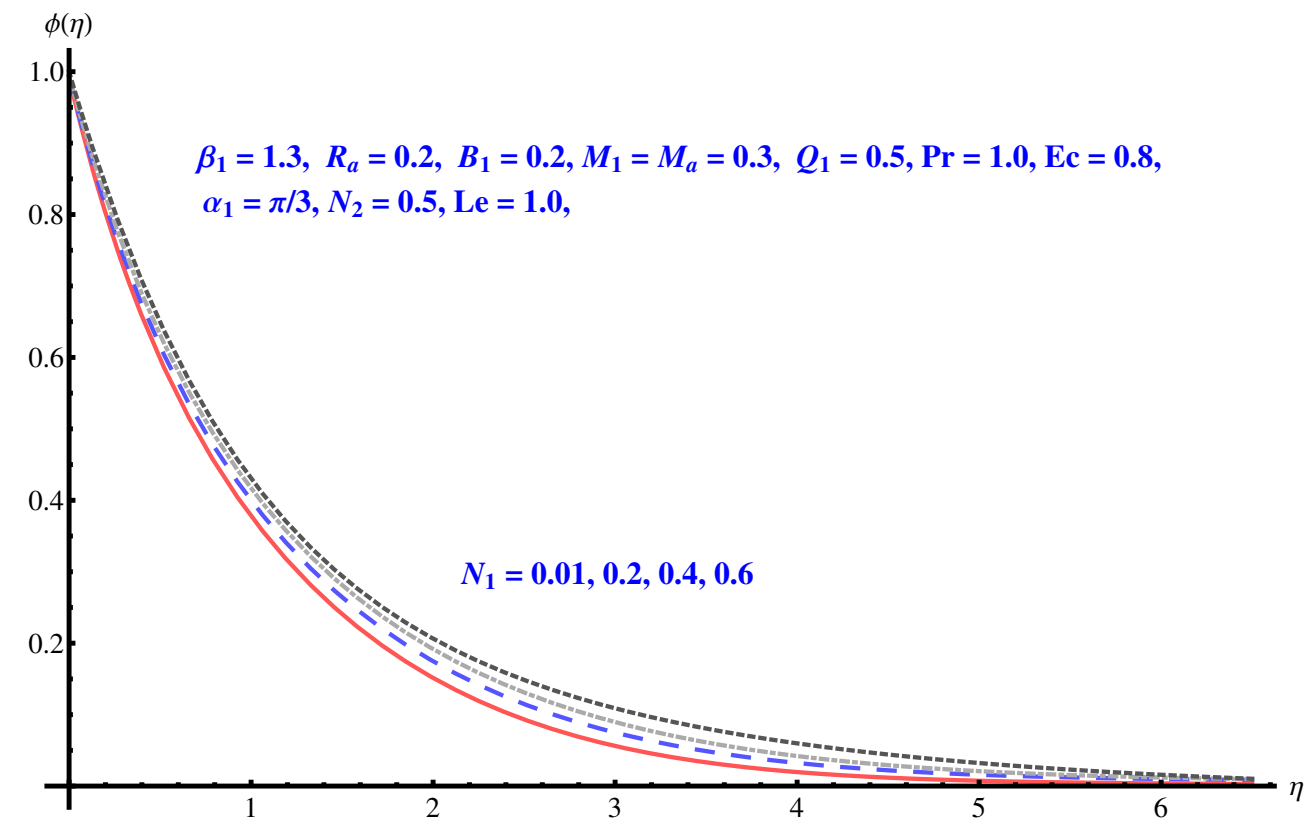

Figure 6. Influence of $N_{1}$ on temperature field. 


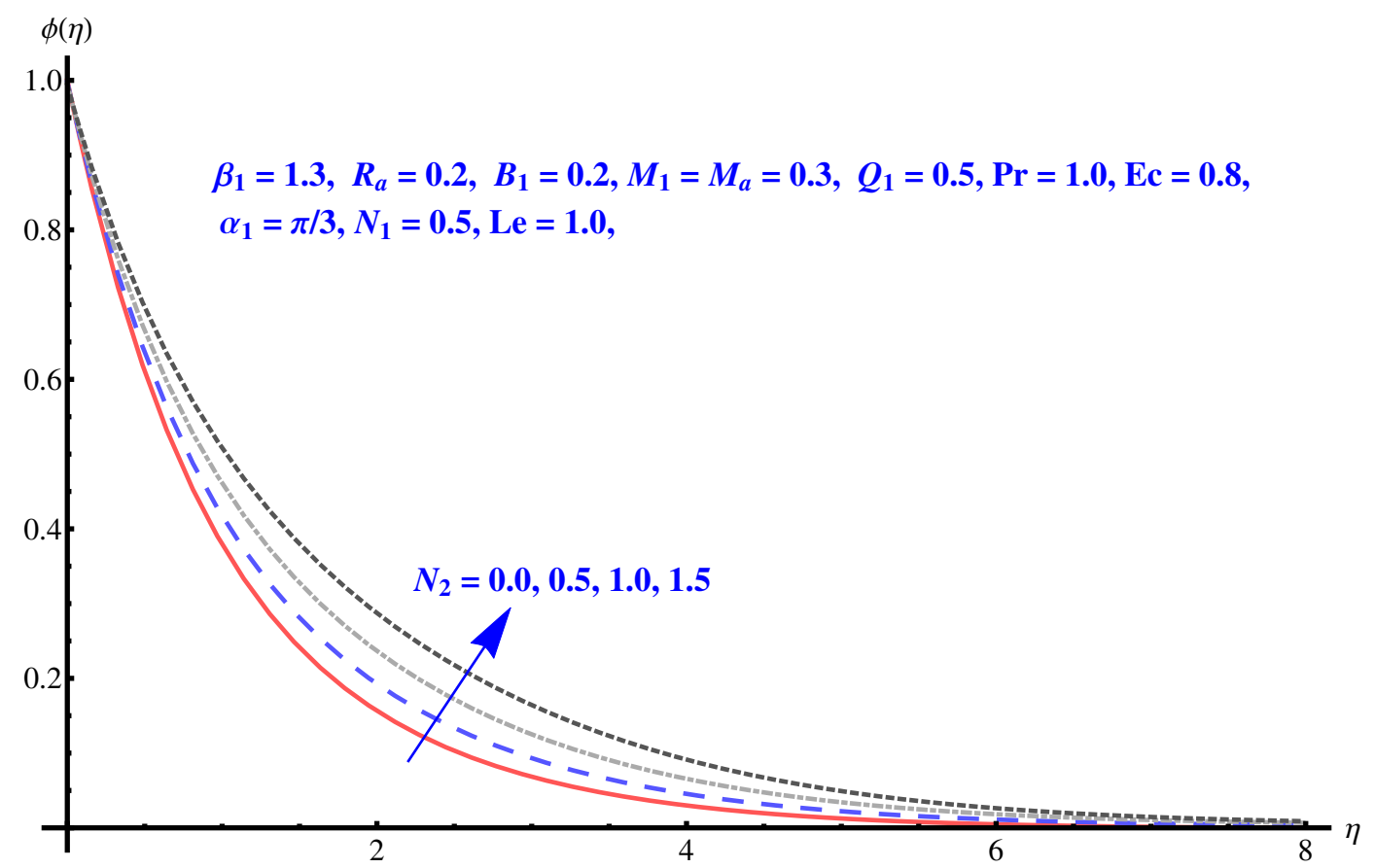

Figure 7. Influence of $\mathrm{N}_{2}$ on temperature field.

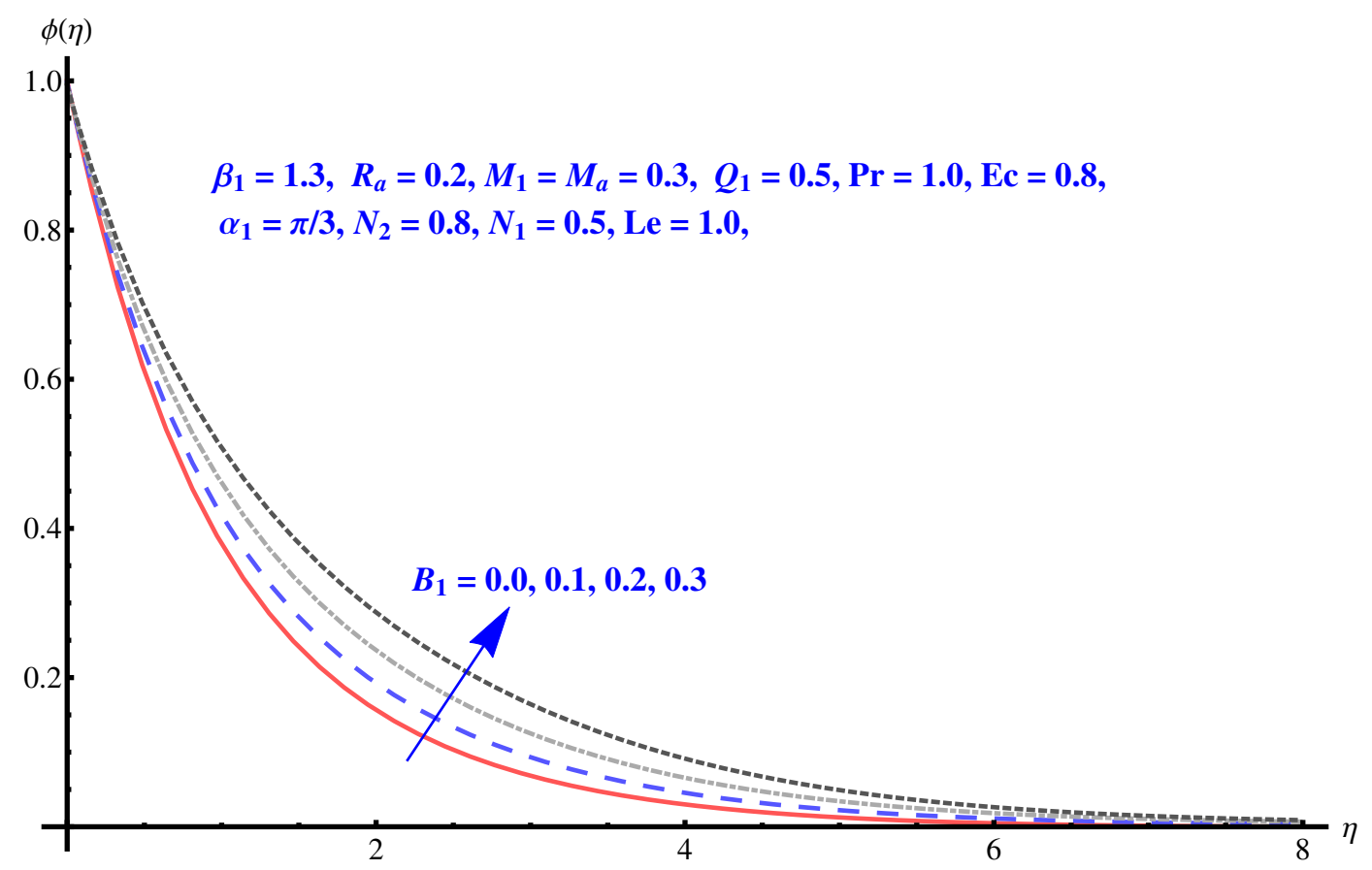

Figure 8. Influence of $B_{1}$ on temperature field.

\subsection{Assessment of Concentration Distribution}

The significance of Brownian motion $N_{1}$ on concentration profile $\zeta(\eta)$ is displayed in Figure 9 . It is observed from the sketch that larger values of $N_{1}$ fluid concentration reduce far away from the surface and vanish after $\eta \geq 5$. On the other side, it increases near the surface. This is due to the existence of slip mechanisms of fluid particles, which influence the hydrodynamic and thermal bounce. Hence, the presence of this terminology does not have significant impact on flow concentration. Further, both thermophoresis parameter $N_{2}$ and Lewis number Le show increasing impact for concentration profiles (see Figures 10 and 11). The improvement in fluid concentration profile via Lewis number Le 
is due to the fact that it is characterized by fluid flows where simultaneously mass and heat transport are involved. Therefore, an improvement is found in fluid concentration.

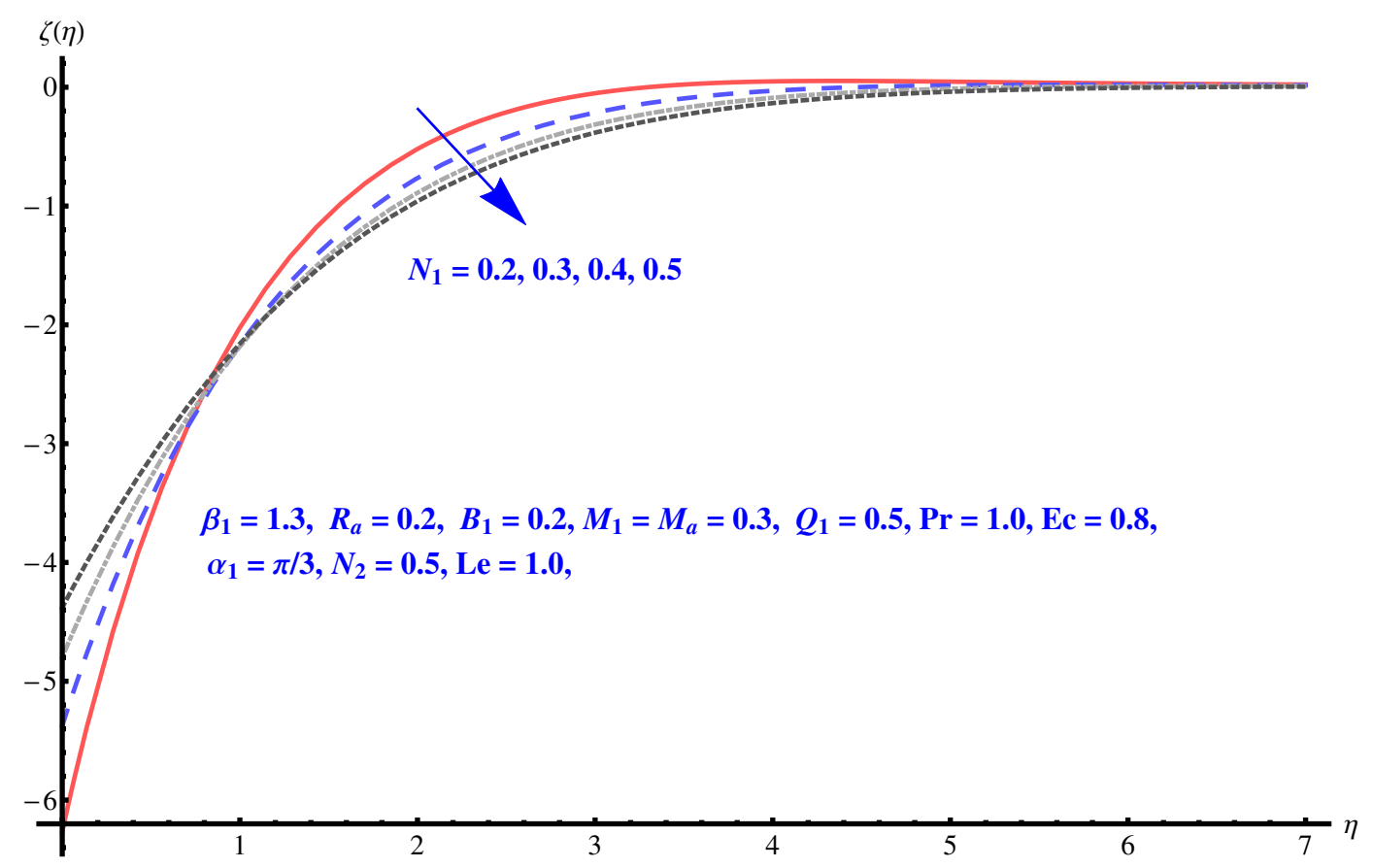

Figure 9. Influence of $N_{1}$ on concentration field.

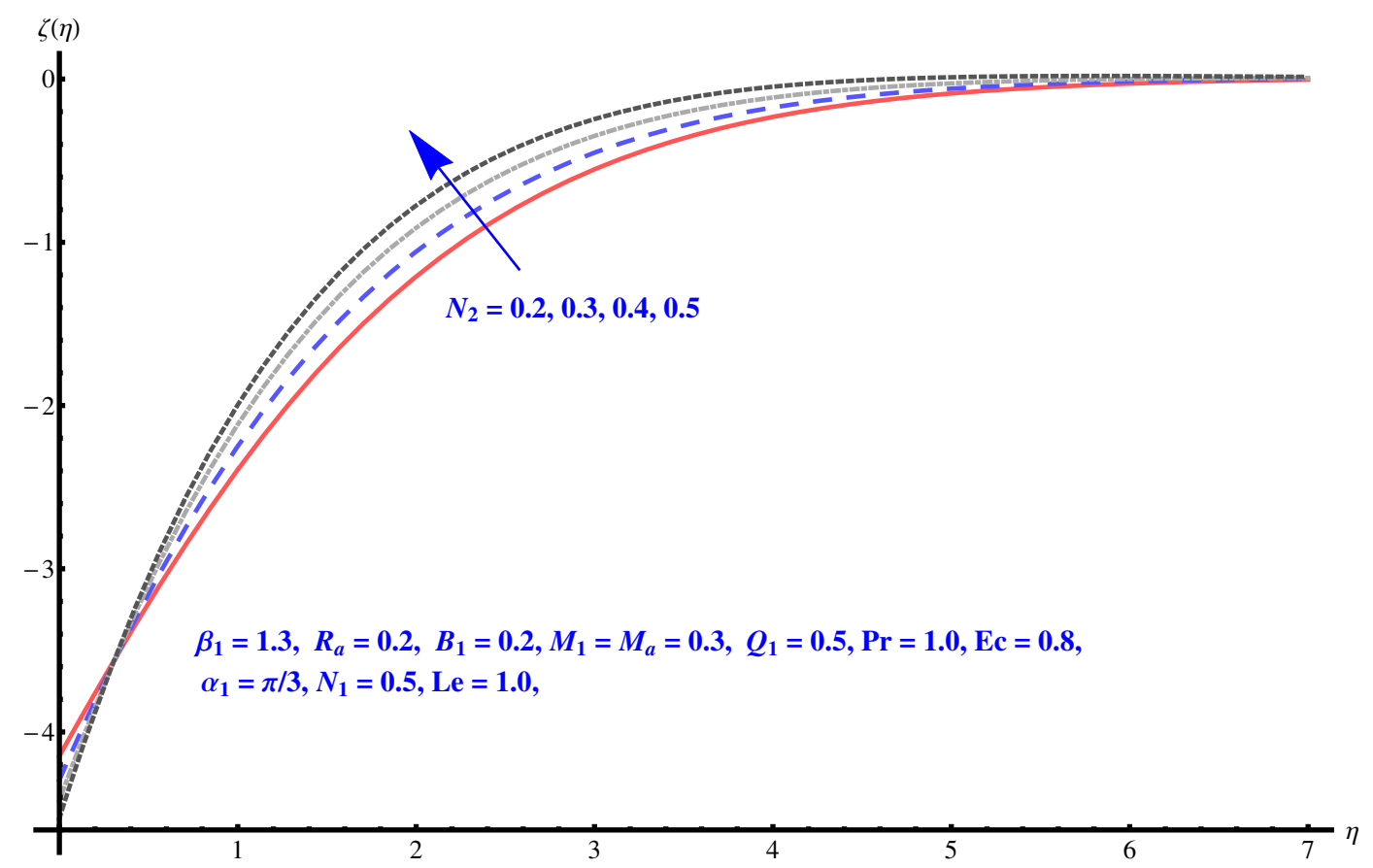

Figure 10. Influence of $\mathrm{N}_{2}$ on concentration field. 


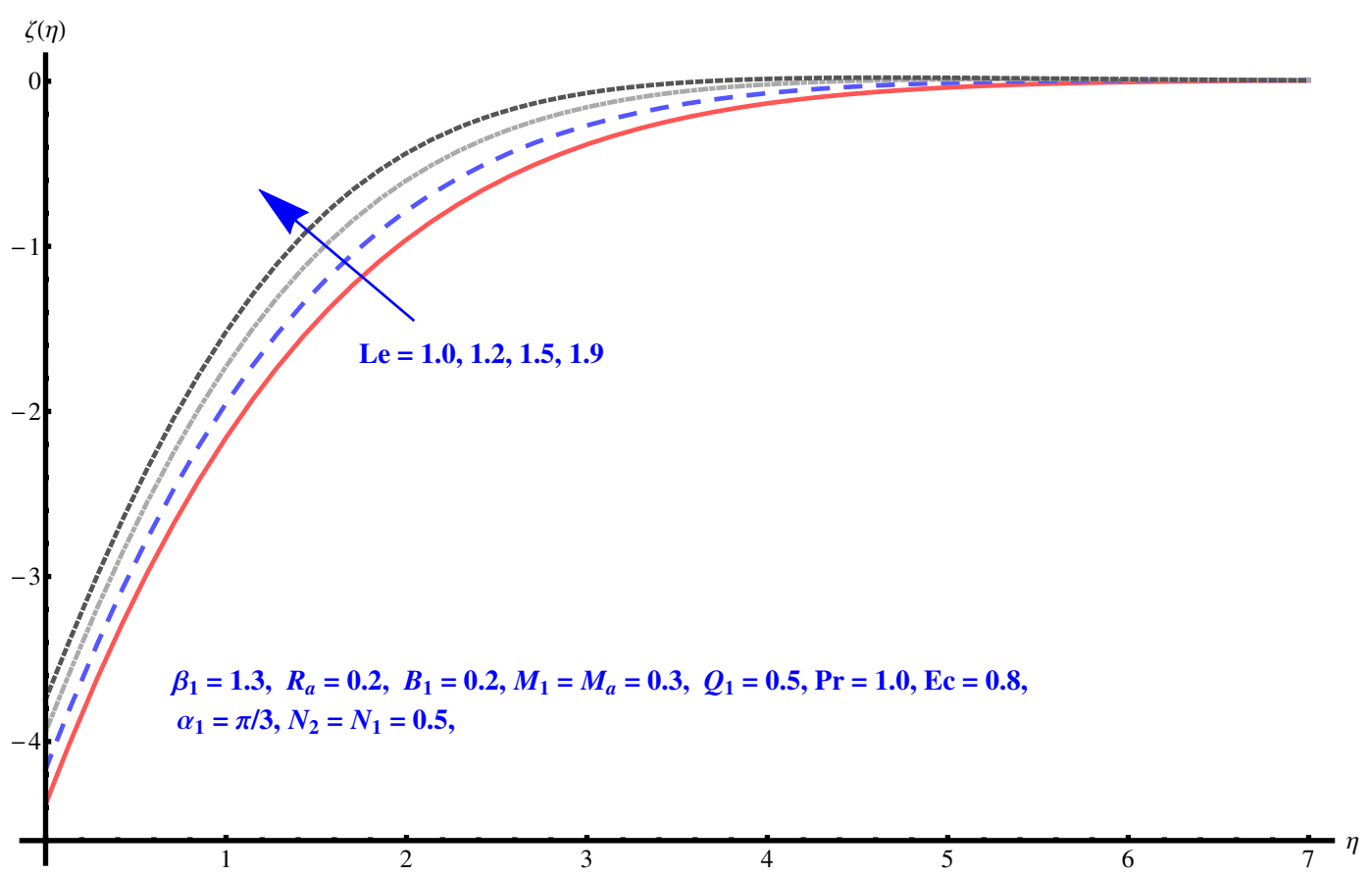

Figure 11. Influence of Le on concentration field.

\subsection{Assessment of local Nusselt Number}

In Table 1, one can see that a good agreement is found between the present results and previous literature. A very good agreement is found in RK-45 results; however, the results of HAM are a little different but the variation trend is similar in all the cases. Table 2 presents the significance of physical parameters through local Nusselt number $\mathrm{N} u$ for axisymmetric Marangoni convective flow of Casson liquid over an infinite disk with the impact of an inclined MHD. Near the wall or boundary, Nusselt number has a dominant role, for the computation of thermal profile variations. The numerical quantities of Nusselt number is supportive to convey the cumulative tendency of temperature gradient in flow domain. It is observed in the table that rises in the Marangoni convective fluid parameter, $M_{a}$, Marangoni ratio, $R_{a}$, and $N_{2}$ monotonically decrease the Nusselt number $N u$ by keeping other fluid parameters fixed. On the other hand, the parameters $N_{1}, \operatorname{Pr}, B_{1}$ and Le manifest rises in heat flux behavior $N u$. The small increase on average Nusselt number indicates that greater heat exchange rate occurs near boundary of the disk due to these parameters.

Table 1. Comparison table of current results with previously published literature setting the additional parameters equals to zero.

\begin{tabular}{|c|c|c|c|c|c|c|}
\hline$r$ & $N_{1}=N_{b}$ & $N_{2}=N_{t}$ & $\mathrm{Pr}$ & $N u_{x}$ (Present) & $N u_{x}([12])$ & $N u_{x}([15])$ \\
\hline 0.0 & & & & 1.488649 & 1.488646 & - \\
\hline 0.1 & & & & 1.551383 & 1.551382 & - \\
\hline \multirow[t]{10}{*}{0.2} & & & & 1.609960 & 1.609962 & - \\
\hline & 0.5 & & & 1.893601 & 1.893601 & - \\
\hline & 1.0 & & & 1.609966 & 1.609962 & - \\
\hline & 1.5 & & & 1.376585 & 1.376584 & - \\
\hline & & 0.5 & & 1.893141 & 1.893141 & - \\
\hline & & 1.0 & & 1.737723 & 1.737723 & - \\
\hline & & 1.5 & & 1.609960 & 1.609962 & - \\
\hline & & & 4.0 & 1.764112 & 1.764332 & 1.535191 \\
\hline & & & 5.0 & 1.767000 & 1.767004 & 1.696162 \\
\hline & & & 6.0 & 1.768490 & 1.768493 & 1.808222 \\
\hline
\end{tabular}


Table 2. Numeric values of local Nusselt parameter $N u$ for distinct values of sundry parameter where $\beta_{1}=1.5, M_{1}=1.0, E c=0.8$ and $\alpha_{1}=\pi / 5$.

\begin{tabular}{cccccccc}
\hline$M_{a}$ & $R_{a}$ & $N_{\mathbf{1}}$ & $N_{\mathbf{2}}$ & $\operatorname{Pr}$ & $B_{1}$ & $L e$ & $-R_{d}^{-1 / 2} N u$ \\
\hline 0.0 & 0.2 & 0.5 & 0.5 & 0.5 & 0.1 & 1.0 & 1.00000 \\
0.3 & & & & & & & 0.99797 \\
0.6 & & & & & & & 0.99772 \\
\hline 0.3 & 0.1 & 0.5 & 0.5 & 0.5 & 0.1 & 1.0 & 0.99966 \\
& 0.3 & & & & & & 0.99690 \\
& 0.5 & & & & & & 0.99588 \\
\hline 0.3 & 0.2 & 0.1 & 0.5 & 0.5 & 0.1 & 1.0 & 0.99657 \\
& & 0.5 & & & & & 0.99797 \\
& & 1.0 & & & & & 0.99966 \\
\hline 0.0 & 0.2 & 0.5 & 0.1 & 0.5 & 0.1 & 1.0 & 0.99962 \\
& & & 0.5 & & & & 0.99797 \\
& & & 1.0 & & & & 0.99549 \\
\hline 0.3 & 0.2 & 0.5 & 0.5 & 0.1 & 0.1 & 1.0 & 0.99755 \\
& & & & 0.7 & & & 0.99797 \\
& & & & 1.2 & & & 0.99857 \\
\hline 0.3 & 0.2 & 0.5 & 0.5 & 0.5 & 0.1 & 1.0 & 0.99829 \\
& & & & & 0.4 & & 0.99979 \\
& & & & & 0.8 & & 1.00009 \\
\hline 0.3 & 0.2 & 0.5 & 0.5 & 0.5 & 0.1 & 1.0 & 0.99829 \\
& & & & & & 1.4 & 0.99883 \\
& & & & & & 1.8 & 0.99923 \\
\hline & & & & & & & \\
\hline
\end{tabular}

\section{Conclusions}

In the present research work, we used RK45 scheme to simulate the two-dimensional Marangoni convective flow along with MHD effect and related heat and mass transfer problem over an infinite disk. The efficiency of proposed model was observed numerically and graphically, and found in good agreement for heat transportation process. The influence of distinct parameters on proposed flow problem are discussed in detail above. Further, the main findings of the present study are highlighted below:

- Increase in Brownian motion parameter enhances the flow temperature field, however the same goes for a declination of concentration field.

- Rise in thermophrases parameter improves the fluid temperature as well as concentration field.

- Larger values of Lewis number corresponds to the high concentration profile.

- Casson fluid parameter is found to be a reducing factor for fluid movement; therefore, admitting the higher quantity of Casson fluid parameter causes a reduction in fluid velocity.

- Increment in magnetic parameter and angle of inclination are reducing factors for the motion of fluid; however, the opposite performance in terms of heat transfer rate via Nusselt number is noted for the two parameters.

- The higher amount of Marangoni number condenses the active connectivity, which leads to improve the velocity profile.

- Temperature distribution rises up for the larger values of heat source sink.

- Increase in the Marangoni and Prandtl numbers show high increment on average Nusselt number, which leads to the conclusion that less heat exchange happens near the disk, while small values of fractional and physical parameters $\beta_{1}, M_{1}, \alpha_{1}, R_{a}, N_{1}, N_{2}, E c, B_{1}$, and Le manifest the high heat exchange rate near the boundary of the disk. 
Author Contributions: Conceptualization, I.Z.; methodology, I.Z.; software, A.S.; validation, G.R.; formal analysis, T.S.K.; investigation, I.Z.; resources, I.T.; data curation, G.R.; writing-original draft preparation, I.Z.; writing—review and editing, A.S., G.R. and I.T.; visualization, A.S.; supervision, T.S.K.; project administration, A.S.; and funding acquisition, I.T.

Funding: This research received no external funding.

Conflicts of Interest: The authors declare no conflict of interest.

\section{References}

1. Hayat, T.; Aziz, A.; Muhammad, T.; Ahmad, B. On magnetohydrodynamic flow of second grade nanofluid over a nonlinear stretching sheet. J. Mag. Mag. Mater. 2016, 408, 99-106. [CrossRef]

2. Hayat, T.; Mumtaz, M.; Shafiq, A.; Alsaedi, A. Stratified magnetohydrodynamic flow of tangent hyperbolic nanofluid induced by inclined sheet. Appl. Math. Mech. 2017, 38, 271-288. [CrossRef]

3. Hayat, T.; Shafiq, A.; Alsaedi, A.; Awais, M. MHD axisymmetric flow of third grade fluid between stretching sheets with heat transfer. Comput. Fluids 2013, 86, 103-108. [CrossRef]

4. Hayat, T.; Shafiq, A.; Nawaz, M.; Alsaedi, A. MHD axisymmetric flow of third grade fluid between porous disks with heat transfer. Appl. Math. Mech. 2012, 33, 749-764. [CrossRef]

5. Shafiq, A.; Hammouch, Z.; Sindhu, T.N. Bioconvective MHD flow of tangent hyperbolic nanofluid with newtonian heating. Int. J. Mech. Sci. 2017, 133, 759-766. [CrossRef]

6. Shateyi, S.; Makinde, D. Numerical analysis of MHD stagnation point flow towards a radially stretching convectively heated disk. In Proceedings of the International Conference on Mechanics, Fluids, Heat, Elasticity and Electromagnetic Fields (MFHEEF 2013), Venice, Italy, 28-30 September 2013; pp. 1-8.

7. Hayat, T.; Shafiq, A.; Alsaedi, A. MHD axisymmetric flow of third grade fluid by a stretching cylinder. Alex. Eng. J. 2015, 54, 205-212. [CrossRef]

8. Shafiq, A.; Nawaz, M.; Hayat, T.; Alsaedi, A. Magnetohydrodynamic axisymmetric flow of a third-grade fluid between two porous disks. Braz. J. Chem. Eng. 2013, 30, 599-609. [CrossRef]

9. Rasool, G.; Zhang, T.; Shafiq, A.; Durur, H. Influence of Chemical Reaction on Marangoni Convective Flow of Nanoliquid in the Presence of Lorentz Forces and Thermal Radiation: A Numerical Investigation. J. Adv. Nanotechnol. 2019, 1, 32-49. [CrossRef]

10. Rasool, G.; Zhang, T.; Shafiq, A. Marangoni Effect in Second Grade Forced Convective Flow of Water Based Nanofluid. J. Adv. Nanotechnol. 2019, 1, 50-61. [CrossRef]

11. Mahanthesh, B.; Gireesha, B.J.; Shashikumar, N.S.; Shehzad, S.A. Marangoni convective MHD flow of SWCNT and MWCNT nanoliquids due to a disk with solar radiation and irregular heat source. Phys. E Low-Dim. Syst. Nanostrut. 2017, 94, 25-30. [CrossRef]

12. Kumar, G.; Gireesha, K.; Prasannakumara, B.J.; Makinde, O.D. Impact of Chemical Reaction on Marangoni Boundary Layer Flow of a Casson Nano Liquid in the Presence of Uniform Heat Source Sink. Diffus. Found. 2017, 11, 22-32. [CrossRef]

13. Din, M.; Usman, S.T.; Afaq, M.; Hamid, K.; Wang, W. Examination of carbon-water nanofluid flow with thermal radiation under the effect of Marangoni convection. Eng. Comput. 2017, 34, 2330-2343.

14. Sheikholeslami, M.; Ganji, D.D. Influence of magnetic field on $\mathrm{CuO}-\mathrm{H}_{2} \mathrm{O}$ nanofluid flow considering Marangoni boundary layer. Int. J. Hydrogen Energy 2017, 42, 2748-2755. [CrossRef]

15. Hayat, T.; Shaheen, U.; Shafiq, A.; Alsaedi, A.; Asghar, S. Marangoni mixed convection flow with Joule heating and nonlinear radiation. AIP Adv. 2015, 5, 1-15. [CrossRef]

16. Besthapu, P.P.; Haq, R.U.; Bandari, S.; Al-Mdallal, Q.M. Thermal radiation and slip effects on MHD stagnation point flow of non-Newtonian nanofluid over a convective stretching surface. Neural Comput. Appl. 2019, 31, 207-217. [CrossRef]

17. Lakshmi, K.B.; Kumar, K.A.; Reddy, J.V.; Sugunamma, V. Influence of nonlinear radiation and cross diffusion on MHD flow of Casson and Walters-B nanofluids past a variable thickness sheet. J. Nanofluids 2019, 8, 73-83. [CrossRef]

18. Casson, N. A flow equation for Pigment-Oil suspensions of the printing ink type. In Rheology Of Disperse Systems; Mill, C.C., Ed.; Pergamon Press: Oxford, London, UK, 1959.

19. Eldabe, N.T.M.; Saddeck, G.; El-Sayed, A.F. Heat transfer of MHD non-Newtonian Casson fluid flow between two rotating cylinders. Mech. Mech. Eng. 2001, 5, 237-251. 
20. Charm, S.E.; Kurland, G. Viscometry of human blood for shear rates of 0-100,000 $\mathrm{sec}^{-1}$. Nature 1965, $206,617$. [CrossRef] [PubMed]

21. Bhattacharyya, K.; Hayat, T.; Alsaedi, A. Analytic solution for magnetohydrodynamic boundary layer flow of Casson fluid over a stretching/shrinking sheet with wall mass transfer. Chin. Phys. B 2013, 22, 1-6. [CrossRef]

22. Kumar, G.; Gireesha, K.; Prasannakumara, B.J.; Ramesh, B.C.; Makinde, O.D. Phenomenon of radiation and viscous dissipation on Casson nanoliquid flow past a moving melting surface. Diffus. Found. 2017, 11, $33-42$. [CrossRef]

23. Vijaya, N.; Krishna, H.; Kalyani, K.; Reddy, G.V.R. Soret and radiation effects on an unsteady flow of a Casson fluid through porous vertical channel with expansion and contraction. Front. Heat Mass Trans. 2018, 1-11. [CrossRef]

24. Hayat, T.; Ashraf, M.B.; Shehzad, S.A.; Alsaedi, A. Mixed Convection Flow of Casson Nanofluid over a Stretching Sheet with Convectively Heated Chemical Reaction and Heat Source/Sink. J. Appl. Fluid Mech. 2015, 8, 803-813. [CrossRef]

25. Ghadikolaei, S.S.; Hosseinzadeh, K.; Ganji, D.D.; Jafari, B. Nonlinear thermal radiation effect on magneto Casson nanofluid flow with Joule heating effect over an inclined porous stretching sheet. Case Stud. Ther. Eng. 2018, 12, 176-187. [CrossRef]

26. Goodarzi, M.; Tlili, I.; Tian, Z.; Safaei, M. Efficiency assessment of using graphene nanoplatelets-silver/water nanofluids in microchannel heat sinks with different cross-sections for electronics cooling. Int. J. Numer. Meth. Heat Fluid Flow 2019. [CrossRef]

27. Afridi, M.I.; Tlili, I.; Goodarzi, M.; Osman, M.; Khan, N.A. Irreversibility analysis of Hybrid nanofluid flow over a thin needle with effects of energy dissipation. Symmetry 2019, 11, 663. [CrossRef]

28. Tlili, I.; Khan, W.A.; Ramadan, K. MHD flow of nanofluid across horizontal circular cylinder: Steady forced convection. J. Nanofluids 2019, 8, 179-186. [CrossRef]

29. Tlili, I.; Khan, W.A.; Ramadan, K. Entropy generation due to MHD stagnation point flow of a nanofluid on a stretching surface in the presence of radiation. J. Nanofluids 2018, 7, 879-890. [CrossRef]

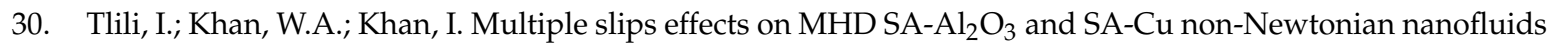
flow over a stretching cylinder in porous medium with radiation and chemical reaction. Res. Phys. 2018, 8, 213-222. [CrossRef]

31. Tlili, I.; Hamadneh, N.N.; Khan, W.A. Thermodynamic analysis of MHD heat and mass transfer of nanofluids past a static wedge with Navier slip and convective boundary conditions. Arab. J. Sci. Eng. 2018, 1-13. [CrossRef]

32. Tlili, I.; Hamadneh, N.N.; Khan, W.A.; Atawneh, S. Thermodynamic analysis of MHD Couette-Poiseuille flow of water-based nanofluids in a rotating channel with radiation and Hall effects. J. Therm. Anal. Calorim. 2018, 132, 1899-1912. [CrossRef]

33. Khan, W.A.; Rashad, A.M.; Abdou, M.M.M.; Tlili, I. Natural bioconvection flow of a nanofluid containing gyrotactic microorganisms about a truncated cone. Eur. J. Mech. B Fluids 2019, 75, 133-142. [CrossRef]

34. Khalid, A.; Khan, I.; Khan, A.; Shafie, S.; Tlili, I. Case study of MHD blood flow in a porous medium with CNTS and thermal analysis. Case Stud. Therm. Eng. 2018, 12, 374-380. [CrossRef]

35. Hayat, T.; Farooq, M.; Alsaedi, A. Thermally stratified stagnation point flow of Casson fluid with slip conditions. Int. J. Numer. Methods Heat Fluid Flow 2015, 25, 724-748. [CrossRef]

36. Mahian, O.; Kianifar, A.; Kalogirou, S.A.; Pop, I.; Wongwises, S. A review of the applications of nanofluids in solar energy. Int. J. Heat Mass Transf. 2013, 57, 582-594. [CrossRef]

37. Wong, K.V.; Leon, O.D. Applications of Nanofluids: Current and Future. Adv. Mech. Eng. 2010. [CrossRef]

38. Hayat, T.; Asad, S. Alsaedi, A. Flow of Casson fluid with nanoparticles. Appl. Math. Mech. 2016, 37, 459-470. [CrossRef]

39. Naseem, A.; Shafiq, A.; Zhao, L.; Farooq, M.U. Analytical investigation of third grade nanofluidic flow over a Riga plate using Cattaneo-Christov model. Res. Phys. 2018, 9, 961-969. [CrossRef]

40. Rasool, G.; Shafiq, A.; Khalique, C.M.; Zhang, T. Magneto-hydrodynamic Darcy-Forchheimer nanofluid flow over nonlinear stretching sheet. Phys. Scr. 2019, 94, 105221. [CrossRef]

41. Rashid, M.; Hayat, T.; Alsaedi, A. Entropy generation in Darcy-Forchheimer flow of nanofluid with five nanoarticles due to stretching cylinder. Appl. Nanosci. 2019, 1-11. [CrossRef] 
42. Naseem, F.; Shafiq, A.; Zhao, L.; Naseem, A. MHD biconvective flow of Powell Eyring nanofluid over stretched surface. AIP Adv. 2017, 7, 1-20. [CrossRef]

43. Rasool, G.; Zhang, T.; Shafiq, A. Second grade nanofluidic flow past a convectively heated vertical Riga plate. Phys. Scr. 2019, 94, 125212. [CrossRef]

44. Rasool, G.; Zhang, T. Characteristics of chemical reaction and convective boundary conditions in Powell-Eyring nanofluid flow along a radiative Riga plate. Heliyon 2019, 5, e01479. [CrossRef] [PubMed]

45. Rasool, G.; Zhang, T. Darcy-Forchheimer nanofluidic flow manifested with Cattaneo-Christov theory of heat and mass flux over non-linearly stretching surface. PLoS ONE 2019, 14, e0221302. [CrossRef] [PubMed]

46. Rasool, G.; Shafiq, A.; Tlili, I. Marangoni convective nano-fluid flow over an electromagnetic actuator in the presence of first order chemical reaction. Heat Transf. Asian Res. 2019, accepted.

47. Rasool, G.; Shafiq, A.; Durur, H. Darcy-Forchheimer Relation in Magnetohydrodynamic Jeffrey Nanofluid Flow over Stretching Surface; Discrete and Continuous Dynamical Systems-Series S; American Institute of Mathematical Sciences, 2019. Available Online: https://www.researchgate.net/publication/336373931_ Darcy-Forchheimer_relation_in_Magnetohydrodynamic_Jeffrey_nanofluid_flow_over_stretching_surface (accessed on 10 October 2019).

48. Rasool, G.; Shafiq, A.; Khalique, C.M. Marangoni Forced Convective Casson Type Nanofluid Flow in the Presence of Lorentz Force Generated by Riga Plate; Discrete and Continuous Dynamical Systems-Series S; American Institute of Mathematical Sciences, 2019. Available Online: https:/ /www.researchgate.net/publication/336373925_Marangoni_forced_convective_Casson_type_ nanofluid_flow_in_the_presence_of_Lorentz_force_generated_by_Riga_plate (accessed on 10 October 2019).

(C) 2019 by the authors. Licensee MDPI, Basel, Switzerland. This article is an open access article distributed under the terms and conditions of the Creative Commons Attribution (CC BY) license (http:/ / creativecommons.org/licenses/by/4.0/). 